\title{
EMG COMPARISON BETWEEN MASTICATORY MUSCLES WHEN USING NARROW DIAMETER IMPLANT ASSISTED MANDIBULAR OVERDENTUES
}

\author{
Mostafa M. Teranelly', Muhammed A. Gad², Adham A. El Ashwah³, Rania A. Fahmy', \\ Wafaa S. Elemary ${ }^{5}$
}

\begin{abstract}
INTRODUCTION: One of the primary objectives of complete dentures is to restore masticatory function in people who have lost their natural teeth. Patients wearing conventional complete denture (CD) often complain of instability of the mandibular denture leading to a feeling of insecurity, inefficient mastication, and overall dissatisfaction with the prosthesis. Implant mandibular overdentures (IOD) constitute a secure therapeutic alternative, affording a great patient's satisfaction and masticatory efficiency. The most common problem in implant dentistry is the presence of insufficient bone volume to receive the conventional size of dental implants. The 2-pieces narrow diameter implants were introduced into the market combining the undisturbed healing period required for proper osseointegration and the avoidance of time, cost and morbidity of extensive surgeries for bone augmentation.

OBJECTIVES: The aim of the current work was to evaluate and compare the electromyographic (EMG) activity of masseter and anterior temporalis muscles when using three different treatment protocols i.e. (conventional CDs, two and four IODs).

MATERIALS AND METHODS: Eight completely edentulous patients were selected from the prosthetic department, Faculty of dentistry, Alexandria University. Implant mandibular assisted overdentures were constructed for each patient using narrow diameter implants and delayed loading protocol. EMG activity of masseter and anterior temporalis muscles during habitual chewing and maximal voluntary clenching were recorded for each of the studied patients in the three different treatment protocols.

RESULTS: EMG activity of masseter and anterior temporalis muscles of IOD was significantly lower with conventional CD than with IOD. Patients with four IOD showed higher EMG activity of masticatory muscles and better function compared to two IOD. Masticatory muscles activity during clenching was significantly higher than during chewing.

CONCLUSIONS: It was concluded that IODs have great masticatory efficiency when compared to CD. Implants number affect masticatory efficiency and muscle activity in cases of severely resorbed mandibular ridge.

KEYWORDS: Narrow implant, overdenture, masticatory efficiency and Electromyography.
\end{abstract}

1- Al-azhr University, Faculty of Dentistry, Cairo, Egypt

2- Professor of Prosthodontics, Alexandria University Faculty of Dentistry, Alex

3- Assist. Prof. Oral and Maxillofacial Surgery, Alexandria University Faculty of Dentistry

4- Lecturer of Oral Medicine \& Periodontology, Alexandria University Faculty of Dentistry

5- Lecturer of Physical Medicine \& Rheumatology, Alexandria University, Faculty of Medicine

Corresponding author:

E-mail: mostafa.terana2017@gmail.com

\section{INTRODUCTION}

The frequent instability of mandibular removable complete dentures causes an alteration of mastication (1). The development of titanium dental implants has extended treatment alternatives for completely edentulous patients using either implant retained fixed or removable prostheses (2).

When the original root-form implants were introduced, they had a diameter of about $3.75 \mathrm{~mm}$. Nowadays, available implants vary in diameter between $1.8 \mathrm{~mm}$ to $6 \mathrm{~mm}$. Implants with diameter less than or equal to $2.9 \mathrm{~mm}$ are called mini dental implants (3), while implants with diameter from $3 \mathrm{~mm}$ to $3.5 \mathrm{~mm}$ are called narrow-diameter implant. (4)

When inadequate bone volume is present for placement of standard diameter implants, most practitioners have been taught to suggest bone grafting. Various augmentation techniques are currently in use to recreate sufficient bone width and height for reliable insertion of endosseous implants but many of them are associated with different problems $(5,6)$.
Unfortunately, the resorption of the alveolar ridges may render the placement of standard diameter implants difficult or impossible in several cases. In this situation, the placement of standard-diameter implant after performing a reconstructive surgery to recreate the correct bone volume and morphology (7) or the simple use of a narrow diameter implant $(8,9)$ may be possible.

Narrow-diameter implants would be beneficial to decrease the morbidity, time and cost of augmentation procedures for implant placement. This might especially help elderly patients or patients with general medical risk factors (10).

Small-diameter implants demonstrated a survival rate similar to those reported in previous studies of standard-size implants $(11,12)$. Using narrow diameter implants may represent a solution to rehabilitate patients with implantsupported prostheses without reconstructive procedures (13).

Finite element study on immediately loaded implants showed that increased implant diameter better dissipated the simulated masticatory force and decreased the stress and strain around the implant neck, especially when the diameter increased from 3.3 to $4.1 \mathrm{~mm}$. It appeared that 
dental implants of $10 \mathrm{~mm}$ in length should be at least 4.1 $\mathrm{mm}$ in diameter for immediate loading (14).

Esposito et al. found that immediate loading can be successful only in selected patients and the trend suggested that immediate loading protocol may fail more often than loading with a delayed protocol (15).

In a systemic review, a wide variety of methods have been used to determine masticatory functions, e.g. measuring colour change in chewing gum, sugar loss from chewing gum, a colorimetric method, photometric methods to quantify changes in colour and optical scanning of chewed particles (16).

Electromyography has also been used to assess the masticatory efficiency of implant mandibular assisted overdentures (17). The EMG activity of a muscle is proportional to the energy consumed to produce contraction. The masseter and anterior temporalis muscles on both sides were evaluated, because they are the largest and strongest of the masticatory muscles, in addition to they are the most superficial and are accessible to EMG examination (17).

This study aimed at studying the EMG activity of masticatory muscles in elderly patients having severely resorbed mandible when using three different treatment protocols.

\section{MATERIALS AND METHODS}

Appropriate ethical clearance was obtained from the research ethics committee. An informed consent was signed by all patients participating in the study.

\section{Inclusion criteria}

All patients were completely edentulous, age of patients ranged from 50 to 70 years. All patients were non-smokers, well motivated, cooperative and with adequate manual dexterity necessary to place a removable implant prosthesis to allow adequate oral hygiene around the endosseous implants. Patients were included if they were in a good health, free from any systemic diseases that might have an effect on the osseointegration of dental implants and of severely resorbed mandibular alveolar ridge but have adequate height and width anteriorly.

\section{Exclusion criteria}

Extremely senile patients as they have poor healing capacity which may affect the surgical phase and osseointegration, uncooperative patients, patients with poor oral hygiene and those who were subjected to chemo-or radiotherapy.

\section{Patient assessment}

Prior to any treatment approach, every patient was thoroughly evaluated regarding both dental and medical status. For this purpose "a patient diagnostic chart" was intended. The chart was designed to include three main points; history, clinical examination and laboratory investigations including (fasting blood glucose test).

\section{Prosthetic phase I (Construction of conventional} complete denture)

Complete maxillary and mandibular dentures (Figure 1) were fabricated for every patient according to standardized conventional techniques.

All subjects were adapted to their dentures for a period of time, minimum two months, to obtain adequate retention, stability and neuromuscular coordination, ensure absence of inflammation or pathologic lesions of oral tissue, and ensure that there was no need for adhesive.

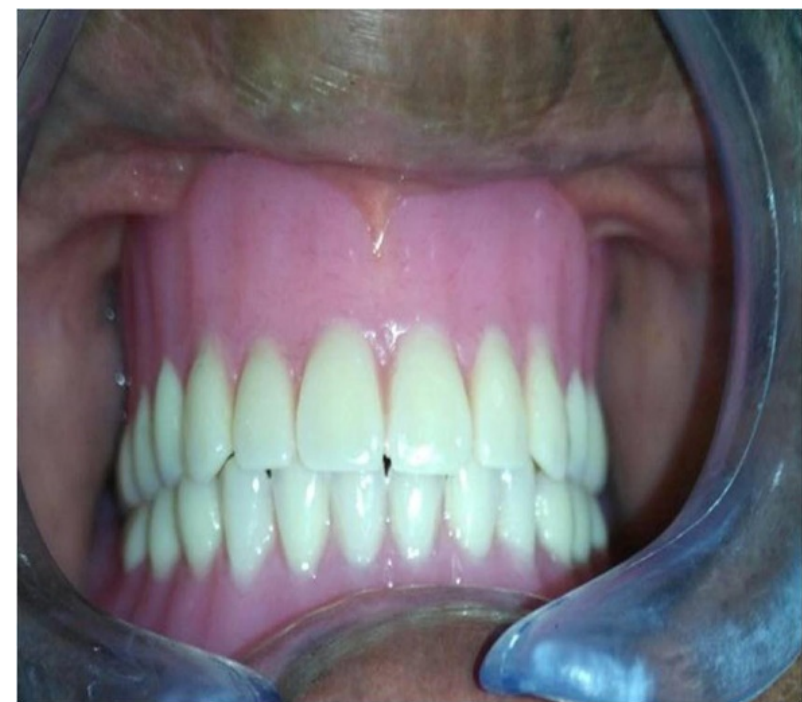

Figure 1:Complete mandibular and maxillary denture was constructed.

\section{Surgical phase I (Implant placement)}

\section{a- Preparation of surgical equipment}

Each patient was evaluated radiographically using cone beam computerized tomography (CBCT). The selection of the interforaminal area of the mandible was based on the recommendation by Lekholm and Zarb (18). Furthermore, it has been established that the survival of the root form titanium implants was very high in the anterior mandible and that the incidence of surgical complications was very low.

A clear acrylic radiographic/surgical mandibular template including gutta-percha radiopaque indicators allowed implant alignment along planned prosthetic axes during implant surgery and ensured good visual access (19) (Figure 2)
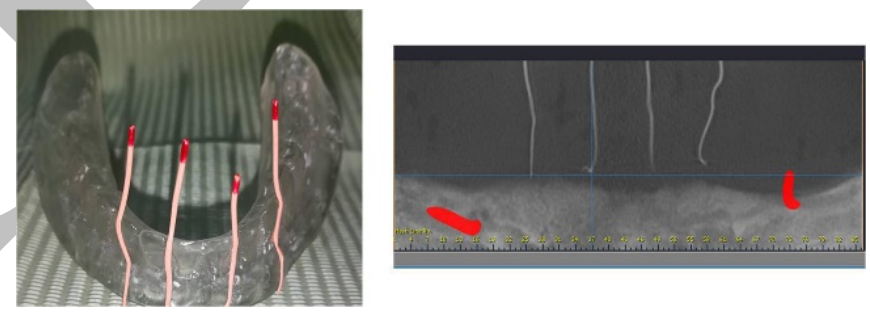

Figure 2: A clear acrylic radiographic/surgical mandibular template including gutta-percha radiopaque indicators.

\section{b- Implants placement according to surgical protocol Surgical phase II (Placement of ball abutments)} a- After three months of implant placement

Two implants were uncovered using a punch. The cover screws were removed. Then the ball abutments were screwed on the implants.

\section{b- After two weeks from uncovering two implants}

The other two implants were uncovered using a punch. The cover screws were removed and the ball abutments were screwed on the implants.

Prosthetic phase II: (Stabilizing and connecting the attachments to the existing mandibular complete denture).

Implant mandibular overdenture fabrication (using ball attachments) was accomplished through the following phases (figure 3): 
- Two ball attachments connected with the implants constructing two IODs.

- The four ball attachments connected with the four implants constructing four IODs
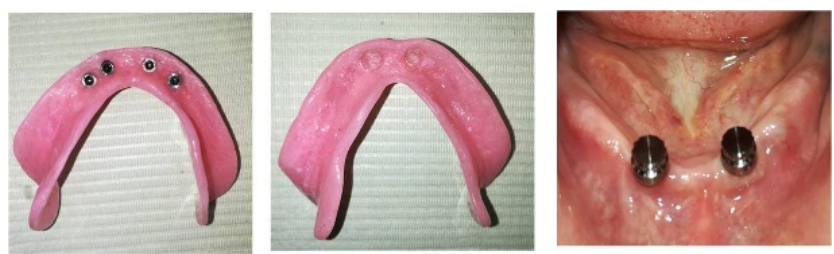

Figure 3: The created two and four metal housing in the fitting surface of the mandibular denture.

\section{Electromyographic evaluation}

EMG activity of masseter and anterior temporalis muscle was assessed bilaterally during habitual chewing of carrots and maximal voluntary clenching (empty clenching) in the three different treatment protocols (CDs, two and four IODs).

EMG activity of masticatory muscles were evaluated at the following periods:

- When using CDs: after 2 months of complete denture construction.

- When using two IODs: after 3 months of implant placement.

- When using four IODs: after 4 months of implant placement.

\section{Statistical analysis}

Data were fed to the computer and analyzed using IBM SPSS software package version 20.0. (Armonk, NY: IBM Corp) Qualitative data were described using number and percent. The Kolmogorov-Smirnov test was used to verify the normality of distribution Quantitative data were described using range (minimum and maximum), mean, standard deviation and median. Significance of the obtained results was judged at the $5 \%$ level. A p-value of less than 0.05 was considered statistically significant. The used tests were Student t-test, ANOVA test and Post Hock Test.

\section{RESULTS}

\section{EMG activity}

Table 1 and 2 demonstrate comparison of the mean values of EMG activity of masseter and anterior temporalis muscles during maximal voluntary clenching (Table 1 and figure 4) and chewing (Table 2 and figure 5) in the three different treatment protocols i.e. (CD, two and four IODs). The mean values of EMG activity of both masseter and anterior temporalis muscles during clenching were significantly higher than during chewing. There was slight side to side difference in EMG activity of muscles of both sides which was sometimes statistically significant (P1 in table 1 and 2).

During clenching and chewing, the mean value of EMG activity of masseter muscles was significantly higher than that of temporalis muscles on both sides in the three situations (P2 in table 1 and 2).

During clenching and chewing, the mean value of EMG activity of masseter and anterior temporalis muscles of IODs was significantly higher than in conventional CDs (P3, P4 in table 1 and 2). In addition, the mean value of EMG activity of four IOD was significantly higher than that of two IOD (P5 in table 1 and 2). (figure 6)
Table (1): Values of EMG activity during clenching.

\begin{tabular}{|c|c|c|c|c|}
\hline \multirow{2}{*}{ Clenching } & \multicolumn{2}{|c|}{ Masseter } & \multicolumn{2}{|c|}{ Anterior temporalis } \\
\hline & Right & Left & Right & Left \\
\hline \multicolumn{5}{|l|}{$\begin{array}{c}\text { Complete } \\
\text { denture }\end{array}$} \\
\hline Range & 91-314 & $87-219$ & $37-201$ & 106-168 \\
\hline Mean & 177.89 & 155.44 & 100.22 & 131.00 \\
\hline S.D & 83.31 & 43.87 & 70.61 & 20.74 \\
\hline P1 & \multicolumn{2}{|c|}{ 0.046* } & \multicolumn{2}{|c|}{$0.021^{*}$} \\
\hline $\mathrm{P} 2$ & & & $0.013^{*}$ & $0.036^{*}$ \\
\hline \multicolumn{5}{|l|}{ Two IODs } \\
\hline Range & $228-710$ & $221-636$ & 79-391 & $164-244$ \\
\hline Mean & 454.63 & 401.33 & 208.00 & 207.25 \\
\hline S.D & 210.53 & 153.15 & 127.40 & 29.34 \\
\hline $\mathrm{P} 1$ & \multicolumn{2}{|c|}{0.089} & \multicolumn{2}{|c|}{0.985} \\
\hline P2 & & & $0.003^{*}$ & $0.0025^{*}$ \\
\hline \multicolumn{5}{|l|}{ Four IODs } \\
\hline Range & $380-712$ & $415-633$ & $104-411$ & $275-549$ \\
\hline Mean & 527.44 & 505.56 & 276.89 & 416.67 \\
\hline S.D & 129.38 & 78.31 & 131.36 & 92.70 \\
\hline $\mathrm{P} 1$ & \multicolumn{2}{|c|}{0.265} & \multicolumn{2}{|c|}{$0.0021^{*}$} \\
\hline $\mathrm{P} 2$ & & & $0.016^{*}$ & $0.002^{*}$ \\
\hline $\begin{array}{c}\text { ANOVA } \\
\mathrm{p}\end{array}$ & $\begin{array}{l}12.25 \\
0.003^{*}\end{array}$ & $\begin{array}{c}8.25 \\
0.011^{*}\end{array}$ & $\begin{array}{l}15.69 \\
0.001^{*}\end{array}$ & $\begin{array}{c}18.65 \\
0.001^{*}\end{array}$ \\
\hline $\begin{array}{c}\text { Post hoc test } \\
\text { P3 } \\
\text { P4 } \\
\text { P5 }\end{array}$ & $\begin{array}{l}0.001^{*} \\
0.001^{*} \\
0.024^{*}\end{array}$ & $\begin{array}{l}0.001^{*} \\
0.002^{*} \\
0.036^{*}\end{array}$ & $\begin{array}{l}0.003^{*} \\
0.001^{*} \\
0.043^{*}\end{array}$ & $\begin{array}{c}0.002^{*} \\
0.0001^{*} \\
0.001^{*}\end{array}$ \\
\hline
\end{tabular}

P1 comparison between right and left in both masseter and anterior temporalis in different group

P2 comparison between masseter and temporalis in each group. ANOVA comparison between the three groups in right and left master and temporalis

P3 comparison between complete dent and two narrow implant P4 comparison between complete dent and four narrow implant $P 5$ comparison between two and four narrow implant

* Significant at level $\leq 0.05$

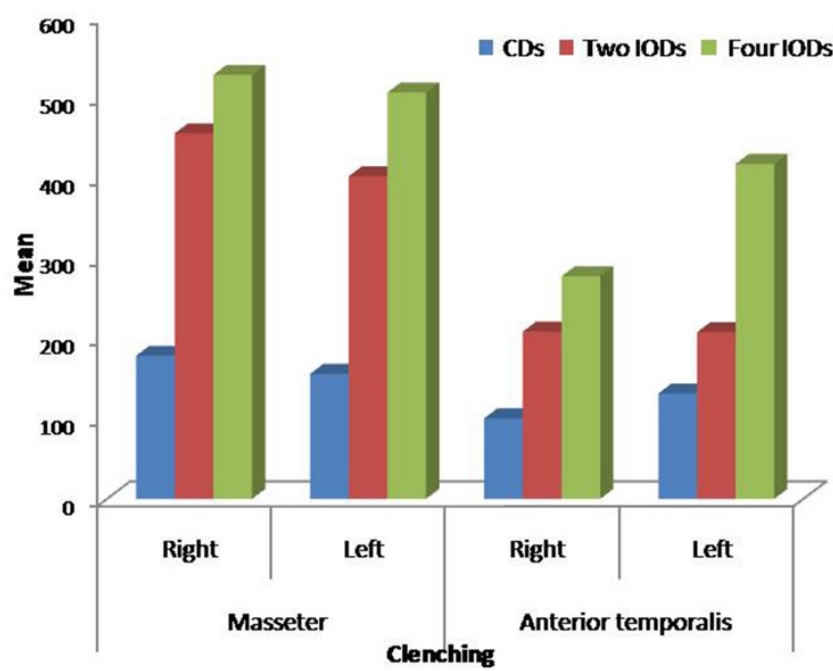

Figure 4: Comparison between the mean values of EMG activity of masseter and anterior temporalis muscle during clenching in different situations (CD, two IOD and four IOD). 
Table (2): Values of EMG activity during chewing.

\begin{tabular}{|c|c|c|c|c|}
\hline \multirow{2}{*}{ Chewing } & \multicolumn{2}{|c|}{ Masseter } & \multicolumn{2}{|c|}{ Anterior temporalis } \\
\hline & Right & Left & Right & Left \\
\hline \multicolumn{5}{|l|}{$\begin{array}{c}\text { Complete } \\
\text { denture }\end{array}$} \\
\hline Range & $81-133$ & $67-117$ & $24-91$ & $21-102$ \\
\hline Mean & 100.89 & 91.11 & 44.50 & 58.63 \\
\hline S.D & 19.68 & 16.05 & 27.72 & 30.24 \\
\hline P1 & \multicolumn{2}{|c|}{0.652} & \multicolumn{2}{|c|}{0.107} \\
\hline P2 & & & $0.0023^{*}$ & $0.016^{*}$ \\
\hline \multicolumn{5}{|l|}{ Two IODs } \\
\hline Range & $142-280$ & $146-305$ & $44-165$ & $55-172$ \\
\hline Mean & 190.75 & 209.50 & 101.56 & 107.78 \\
\hline S.D & 51.38 & 61.98 & 44.22 & 45.83 \\
\hline P1 & \multicolumn{2}{|c|}{$0.003 *$} & \multicolumn{2}{|c|}{0.658} \\
\hline P2 & & & $0.036^{*}$ & $0.004 *$ \\
\hline \multicolumn{5}{|l|}{ Four IODs } \\
\hline Range & $167-332$ & $198-371$ & $121-283$ & $104-257$ \\
\hline Mean & 245.75 & 298.38 & 199.25 & 162.63 \\
\hline S.D & 53.55 & 66.36 & 70.45 & 52.93 \\
\hline P1 & \multicolumn{2}{|c|}{0.107} & \multicolumn{2}{|c|}{0.123} \\
\hline P2 & & & $0.035 *$ & $0.002 *$ \\
\hline $\begin{array}{l}\text { ANOVA } \\
P\end{array}$ & $\begin{array}{c}14.65 \\
0.0021^{*}\end{array}$ & $\begin{array}{c}16.02 \\
0.001^{*}\end{array}$ & $\begin{array}{c}6.98 \\
0.036^{*}\end{array}$ & $\begin{array}{c}11.6 \\
0.005^{*}\end{array}$ \\
\hline $\begin{array}{c}\text { Post hoc test } \\
\text { P3 } \\
\text { P4 } \\
\text { P5 }\end{array}$ & $\begin{array}{l}0.002 * \\
0.001 * \\
0.003 *\end{array}$ & $\begin{array}{c}0.001^{*} \\
0.0001^{*} \\
0.008^{*}\end{array}$ & $\begin{array}{l}0.003^{*} \\
0.001^{*} \\
0.014^{*}\end{array}$ & $\begin{array}{l}0.006^{*} \\
0.001^{*} \\
0.042^{*}\end{array}$ \\
\hline
\end{tabular}

P1 comparison between right and left in both masseter and anterior temporalis in different group

P2 comparison between masseter and temporalis in each group. ANOVA comparison between the three groups in right and left master and temporalis

P3 comparison between complete dent and two narrow implant P4 comparison between complete dent and four narrow implant P5 comparison between two and four narrow implant * Significant at level $\leq 0.05$
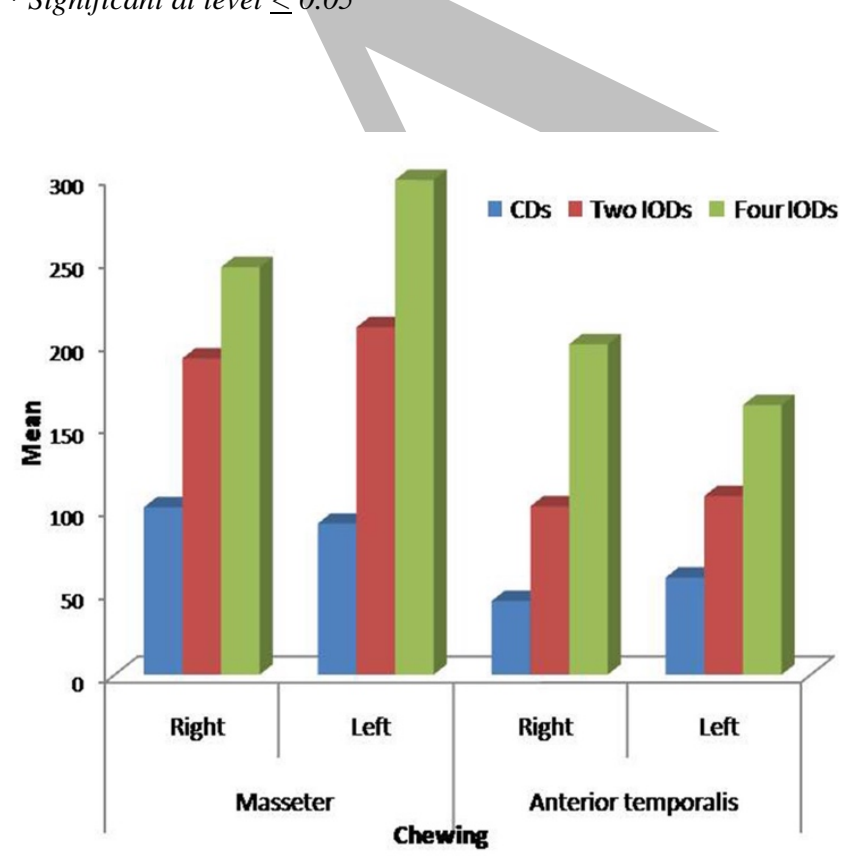

Figure 5: Comparison between the mean values of emg activity of masseter and anterior temporalis muscle during chewing in different situations (cd, two iod and four iod).

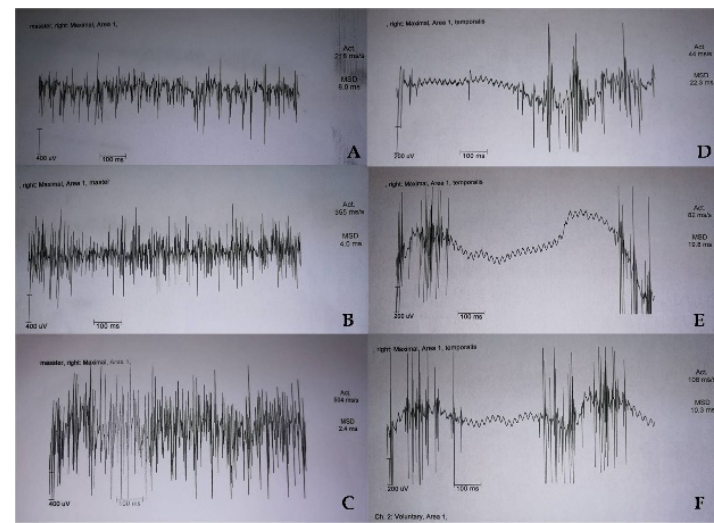

Figure 6:Comparison between EMG activity of masseter and anterior temporalis muscle during clenching (A, B and C) and chewing (D, E and F) in the three different treatment protocols i.e. (CD, two IOD and four IOD) in one of the studied patient.

\section{DISCUSSION}

A mandibular implant assisted over denture is an excellent treatment option for completely edentulous patients providing great patient's satisfaction than conventional complete dentures (20).

Various numbers of implants have been recommended. The McGill consensus statement reported that overdentures supported by two dental implants are a routine procedure in the dental practice (21). Overdentures assisted by four implants have been suggested as one of the treatment options for edentulous patients at specific situations (22).

Insufficient bone width for insertion of dental implant of conventional size is the most common problem in implant dentistry (23). In cases where bone width is narrow, local bone augmentation to enable the use of standard-size implants may be compromised due to several complications $(5,6)$. The other treatment option is the use of smaller diameter implant that is less invasive (8).

Results obtained from literatures indicated that narrow diameter implant is a predictable treatment option, since they afford clinical results comparable to those obtained with implants of standard diameter (11-13, 24).

Conventional size of dental implants can be loaded immediately or delayed depending on specific factors (25).

When narrow implants were introduced, they were single pieces (26). Now, two-pieces narrow implants were introduced into the market and allowed insertion into bone with a lower density with delayed loading after 3 to 6 months, same as with conventional size.

Various methods were used for evaluation of masticatory efficiency (16). In the current study, electomyography was used for estimation of masticatory efficacy of both masseter and anterior temporalis muscles during chewing and muscle activity during clenching.

In the present study, the subjective assessment of the masticatory efficiency using questionnaire revealed that all subjects with two and four IODs were more satisfied with stability of their dentures and their overall oral function compared with the previous situation.

In the current work, the masseter muscles showed higher EMG activity when compared with the temporalis muscles during chewing and clenching in the three situations (CDs, two and four IODs). This observation runs in agreement with several studies (27-30). This may be explained by the location of the muscle on the mandible and fulcrum. 
In addition, EMG activity of both anterior temporalis and masseter muscles during clenching were higher than during chewing. This was in agreement with (Ciccone et al and Oncins et al) $(30,31)$. This might be because clenching required increased muscle activity to allow jaw movements required for exerting cutting and grinding forces.

The current work showed higher EMG activity of masseter and anterior temporalis muscles with two IOD when compared to that with conventional CDs. This could be explained by enhancement of support, retention and stability of the dentures making the patients more comfortable, reducing mucosal pain and allowing high confidence during social interactions $(32,33)$. These results agreed with the observations of different investigators (3437).

The current study also revealed that patients with four IODs, when using narrow implants with ball attachments and delayed loading protocol, had significantly better EMG activity of masseter and anterior temporalis muscles compared to those with two IODs. This might be because by increasing number of implants, the load on the oral mucosa was decreased and hence oral pain was reduced during functions.

Contrary to the current study results, Ucankale et al. found no difference in maximum bite force and muscle activity between two and four implants supporting a mandibular overdenture with bar attachments. This might be related to the ridge form, volume and implants diameter more than $3.5 \mathrm{~mm}$ (38).

Stellingsma et al. (39) analyzed the effects of implant assisted overdentures on masticatory function in patients with extremely resorbed mandibles, and compared masticatory function using 3 differing types of implant treatment protocols. Masticatory function was assessed before and after treatment using a questionnaire, a masticatory performance test, and a structured interview. It was concluded that there was a significant improvement in masticatory function after implant assisted overdenture treatment. However, the differences in masticatory function between the 3modalities were not significant after treatment, regardless dental implants number.

\section{CONCLUSION}

Using narrow diameter implants reduced invasiveness, cost and time of bone grafting surgical procedures. In case of severely resorbed mandible, using only two narrow implants to support overdenture was not enough to reduce oral pain. In these cases, placement of four narrow implants improved the masticatory efficiency, muscle activity and reduced the mucosal pain.

\section{CONFLICT OF INTEREST}

The authors declare that they have no conflicts of interest.

\section{REFERENCES}

1. Huumonen S, Haikola B, Oikarinen K, Soderholm AL, Remes-Lyly T, Sipila K. Residual ridge resorption, lower denture stability and subjective complaints among edentulous individuals. J Oral Rehabil. 2012;39:384-90.

2. Branemark P-I. Osseointegration and its experimental background. J Prosthet Dent. 1983;50:399-410.

3. Christensen GJ. The 'mini'-implant has arrived. J Am Dent Assoc. 2006;137:387-90.
4. Andersen E, Saxegaard E, Knutsen BM, Haanaes HR. A prospective clinical study evaluating the safety and effectiveness of narrow-diameter threaded implants in the anterior region of the maxilla. Int J Oral Maxillofac Implants. 2001;16:217-24.

5. Chiapasco M, Zaniboni M, Boisco M. Augmentation procedures for the rehabilitation of deficient edentulous ridges with oral implants. Clin Oral Implants Res. 2006;17:136-59.

6. Nkenke E, Weisbach V, Winckler E, Kessler P, Schultze-Mosgau S, Wiltfang J, et al. Morbidity of harvesting of bone grafts from the iliac crest for preprosthetic augmentation procedures: a prospective study. Int J Oral Maxillofac Surg. 2004;33:157-63.

7. Chiapasco M, Casentini P, Zaniboni M. Bone augmentation procedures in implant dentistry. Int J Oral Maxillofac Implants. 2009;24:237-59.

8. Chiapasco M, Casentini P, Zaniboni M, Corsi E, Anello T. Titanium-zirconium alloy narrow-diameter implants (Straumann Roxolid (R)) for the rehabilitation of horizontally deficient edentulous ridges: prospective study on 18 consecutive patients. Clin Oral Implants Res. 2012;23:1136-41.

9. Galindo-Moreno P, Nilsson P, King P, Becktor J, Speroni S, Schramm A, et al. Clinical and radiographic evaluation of early loaded narrow diameter implants - 1year follow-up. Clin Oral Implants Res. 2012;23:60916.

10. Davarpanah M, Martinez H, Tecucianu JF, Celletti R, Lazzara R. Small-diameter implants: indications and contraindications. J Esthet Dent. 2000;12:186-94.

11. Morneburg TR, Proschel PA. Success rates of microimplants in edentulous patients with residual ridge resorption. Int J Oral Maxillofac Implants. 2008;23:2706.

12. Al-Nawas B, Bragger U, Meijer HJ, Naert I, Persson R, Perucchi A, et al. A double-blind randomized controlled trial (RCT) of Titanium-13Zirconium versus Titanium Grade IV small-diameter bone level implants in edentulous mandibles--results from a 1-year observation period. Clin Implant Dent Relat Res. 2012;14:896-904.

13. Cho SC, Froum S, Tai CH, Cho YS, Elian N, Tarnow DP. Immediate loading of narrow-diameter implants with overdentures in severely atrophic mandibles. Pract Proced Aesthet Dent. 2007;19:167-74.

14. Ding X, Zhu XH, Liao SH, Zhang XH, Chen H. Implantbone interface stress distribution in immediately loaded implants of different diameters: a three-dimensional finite element analysis. J Prosthodont. 2009;18:393-402.

15. Esposito M, Grusovin MG, Coulthard P, Worthington HV. Different loading strategies of dental implants: a Cochrane systematic review of randomised controlled clinical trials. Eur J Oral Implantol. 2008;1:259-76.

16. Oliveira NM, Shaddox LM, Toda C, Paleari AG, Pero AC, Compagnoni MA. Methods for evaluation of masticatory efficiency in conventional complete denture wearers: a systematized review. Oral Health Dent Manag. 2014;13:757-62.

17. Elsyad MA, Hegazy SA, Hammouda NI, Al-Tonbary GY, Habib AA. Chewing efficiency and electromyographic activity of masseter muscle with three designs of implant-supported mandibular overdentures. A cross-over study. Clin Oral Implants Res. 2014;25:742-8. 
18. Lekholm U, Zarb GA. Patient selection and preparation. In: Branemark PI, Zarb GA, Albrektsson T (eds). Tissue integrated prostheses: osseointegration in clinical dentistry. Chicago: Quintessence Publishing Company; 1985. p 199-209.

19. Wulfman C, Hadida A, Rignon-Bret C. Radiographic and surgical guide fabrication for implant-retained mandibular overdenture. J Prosthet Dent. 2010;103:537.

20. Boerrigter EM, Geertman ME, Van Oort RP, Bouma J, Raghoebar GM, van Waas MA, et al. Patient satisfaction with implant-retained mandibular overdentures. A comparison with new complete dentures not retained by implants--a multicentre randomized clinical trial. Br J Oral Maxillofac Surg. 1995;33:282-8.

21. Feine JS, Carlsson GE, Awad MA, Chehade A, Duncan WJ, Gizani S, et al. The McGill consensus statement on overdentures. Mandibular two-implant overdentures as first choice standard of care for edentulous patients. Montreal, Quebec, May 24-25, 2002. Int J Oral Maxillofac Implants. 2002;17:601-2.

22. Meijer HJ, Raghoebar GM, Batenburg RH, Visser A, Vissink A. Mandibular overdentures supported by two or four endosseous implants: a 10-year clinical trial. Clin Oral Implants Res. 2009;20:722-8.

23. Kendrick S, Wong D. Vertical and horizontal dimensions of implant dentistry: numbers every dentist should know. Inside Dent. 2009:e4287.

24. Sierra-Sanchez JL, Martinez-Gonzalez A, Garcia-Sala Bonmati F, Manes-Ferrer JF, Brotons-Oliver A. Narrow-diameter implants: are they a predictable treatment option? A literature review. Med Oral Patol Oral Cir Bucal. 2014;19:e74-81.

25. Cochran DL, Morton D, Weber HP. Consensus statements and recommended clinical procedures regarding loading protocols for endosseous dental implants. Int J Oral Maxillofac Implants. 2004;19:10913.

26. Esposito M, Grusovin MG, Chew YS, Coulthard P, Worthington HV. One-stage versus two-stage implant placement. A Cochrane systematic review of randomised controlled clinical trials. Eur J Oral Implantol. 2009;2:91-9.

27. Elsyad MA, Hegazy SA, Hammouda NI, Al-Tonbary GY, Habib AA. Chewing efficiency and electromyographic activity of masseter muscle with three designs of implant-supported mandibular overdentures. A cross-over study. Clin Oral Implants Res. 2014;25:742-8.

28. Abdelhamid A, Metwally N, Imam M. The effect of two different attachments with implant retained mandibular overdentures on the masticatory function. J Dent Oral Disord Ther. 2016;4:1-9.

29. Kimoto K, Fushima K, Tamaki K, Toyoda M, Sato S, Uchimura N. Asymmetry of masticatory muscle activity during the closing phase of mastication. Cranio. 2000;18:257-63.

30. Oncins MC, Vieira MM, Bommarito S. Electromyography of the masticatory muscles: analysis in the original and RMS value. Revista CEFAC. 2014;16:1215-21.

31. Ciccone de Faria Tdos S, Hallak Regalo SC, Thomazinho A, Vitti M, de Felicio CM. Masticatory muscle activity in children with a skeletal or dentoalveolar open bite. Eur J Orthod. 2010;32:453-8.

32. Preoteasa E, Imre M, Lerner H, Tancu AM, Preoteasa CT. Narrow Diameter and Mini Dental Implant Overdentures. Emerging Trends in Oral Health Sciences and Dentistry: In Tech; 2015.

33. Burns DR, Unger JW, Elswick RK Jr, Beck DA. Prospective clinical evaluation of mandibular implant overdentures: Part I--Retention, stability, and tissue response. J Prosthet Dent. 1995;73:354-63.

34. Bakke M, Holm B, Gotfredsen K. Masticatory function and patient satisfaction with implant-supported mandibular overdentures: a prospective 5-year study. Int J Prosthodont. 2002;15:575-81.

35. van Kampen FM, van der Bilt A, Cune MS, Bosman F. The influence of various attachment types in mandibular implant-retained overdentures on maximum bite force and EMG. J Dent Res. 2002;81:170-3.

36. Karkazis HC. EMG activity of the masseter muscle in implant supported overdenture wearers during chewing of hard and soft food. J Oral Rehabil. 2002;29:986-91.

37. von der Gracht I, Derks A, Haselhuhn K, Wolfart S. EMG correlations of edentulous patients with implant overdentures and fixed dental prostheses compared to conventional complete dentures and dentates: a systematic review and meta-analysis. Clin Oral Implants Res. 2017;28:765-73.

38. Ucankale M, Akoglu B, Ozkan Y, Ozkan YK. The effect of different attachment systems with implant-retained overdentures on maximum bite force and EMG. Gerodontology. 2012;29:24-9.

39. Stellingsma K, Slagter AP, Stegenga B, Raghoebar GM, Meijer HJ. Masticatory function in patients with an extremely resorbed mandible restored with mandibular implant-retained overdentures: comparison of three types of treatment protocols. J Oral Rehabil. 2005;32:403-10

40. Zitzmann NU, Marinello CP. [Patient satisfaction with removable implant-supported prostheses in the edentulous mandible]. Schweiz Monatsschr Zahnmed. 2006;116:237-44. 